University of Nebraska - Lincoln

DigitalCommons@University of Nebraska - Lincoln

USGS Northern Prairie Wildlife Research Center

US Geological Survey

2012

\title{
Development of Camera Technology for Monitoring Nests
}

\author{
W. Andrew Cox \\ University of Missouri - Columbia, wac253@mail.missouri.edu \\ M. Shane Pruett \\ Archbold Biological Station, spruett@archbold-station.org \\ Thomas J. Benson \\ University of Illinois at Urbana-Champaign, tjbenson@illinois.edu \\ Scott J. Chiavacci \\ Arkansas State University, schiavacci@gmail.com \\ Frank R. Thompson III \\ University of Missouri - Columbia, frthompson@fs.fed.us
}

Follow this and additional works at: https://digitalcommons.unl.edu/usgsnpwrc

Part of the Other International and Area Studies Commons

Cox, W. Andrew; Pruett, M. Shane; Benson, Thomas J.; Chiavacci, Scott J.; and Thompson, Frank R. III, "Development of Camera Technology for Monitoring Nests" (2012). USGS Northern Prairie Wildlife Research Center. 250.

https://digitalcommons.unl.edu/usgsnpwrc/250

This Article is brought to you for free and open access by the US Geological Survey at DigitalCommons@University of Nebraska - Lincoln. It has been accepted for inclusion in USGS Northern Prairie Wildlife Research Center by an authorized administrator of DigitalCommons@University of Nebraska - Lincoln. 


\title{
Development of Camera Technology for Monitoring Nests
}

\author{
W. Andrew Cox, M. Shane Pruett, Thomas J. Benson, \\ Scott J. Chiavacci, and Frank R. Thompson III
}

\begin{abstract}
Photo and video technology has become increasingly useful in the study of avian nesting ecology. However, researchers interested in using camera systems are often faced with insufficient information on the types and relative advantages of available technologies. We reviewed the literature for studies of nests that used cameras and summarized them based on study objective and the type of technology used. We also designed and tested two video systems that we used for three nest predator and behavioral studies. We found 327 studies that recorded 255 bird species spanning 19 orders. Cameras were most commonly used to study nest predators $(n=114)$, feeding ecology ( $n=103)$, and adult behavior $(n=81)$. Most systems (69\%) were partially or completely user-built. Systems that recorded in real time ( $\geq 25$ frames per second), time-lapse $(<25 \mathrm{fps}$ ), and still images were all common, though their use tended to vary by study objective. Using the
\end{abstract}

time-lapse digital video recording systems we designed, we monitored 184 nests of 15 different species. We generally found these low-cost systems (US\$350-725 per unit) to be reliable. Sources of data loss were variable by study but included digital recorder malfunction, power failure, and video cable damage due to rodents. Our review of the literature and our own experiences suggest that researchers carefully consider their objectives and study systems when choosing camera technology. To facilitate selection of the appropriate system, we describe general video system design and offer recommendations for researchers based on commercially available system components.

Key Words: behavior, camera, digital video recorder, nest monitoring, parental care, photography, predation, time-lapse, video. n 1956, Gysel and Davis presented an "automatic photographic unit for wildlife research," which they baited with dove eggs to identify potential predators. Three years later, Royama (1959) published the specifications for an "auto- cinematic food-recorder" which automatically triggered photographs of prey in the bills of Great Tits (Parus major) each time they perched on a trigger mechanism at the entrance of their nest-box. In the subsequent 50 years, ornithologists have employed

Cox, W. A., M. S. Pruett, T. J. Benson, S. J. Chiavacci, and F. R. Thompson III, 2012. Development of camera technology for monitoring nests. Pp. 185-210 in C. A. Ribic, F. R. Thompson III, and P. J. Pietz (editors). Video surveillance of nesting birds. Studies in Avian Biology (no. 43), University of California Press, Berkeley, CA.

This article is a U.S. government work, and is not subject to copyright in the United States. 
photo and video technology to study birds at their nests with increasing frequency. Such technology allows for the collection of data that would otherwise be impractical to obtain because of logistical and/or financial constraints. Common research questions that can be addressed with cameras include nest predator identification (Hussell 1974, Thompson et al. 1999, Pietz and Granfors 2000), parental care (Grundel 1987, Cartar and Montgomerie 1987), prey identification (Hanula and Franzreb 1995, Grønnesby and Nygård 2000), and nestling behavior (McRae et al. 1993, Nathan et al. 2001). Cameras also provide researchers with glimpses of extremely rare events or unknown behaviors [egg and nestling cannibalism (Gilbert et al. 2005, Ben-Dov et al. 2006); helping at nests of non-cooperatively breeding species (Guzy et al. 2002)] that would otherwise go undetected.

Despite the obvious value and increasingly common use of camera technology, ornithologists are often faced with more questions than answers when it comes to deciding on the type of equipment to use. Furthermore, reliable implementation of wildlife surveillance equipment is sometimes easier said than done; adverse field conditions or a lack of technical expertise can seriously hinder data collection. There have been two previous literature reviews that offered guidance on the video surveillance of nests. Cutler and Swann (1999) provided a useful guide to equipment based on study objectives, though it is now more than a decade old and provides little practical technical help given the rapid pace of innovation. Reif and Tornberg (2006) filled this gap in their more recent review, which focuses on use of digital video systems. Both papers should be read by any researcher interested in using cameras at avian nests. Our objectives were to (1) provide an updated review of camera studies focusing on the technology used to address common research questions, (2) report on user-built systems we used to monitor nests, and (3) provide recommendations on technical aspects of video systems for nest surveillance.

\section{METHODS}

\section{Literature Review}

In January 2009 we used Biblioline Wildlife and Ecology Studies Worldwide and Scopus to find original, peer-reviewed research which used camera technology to monitor avian nests. We used the keyword nest with keywords photo, video, or camera. We read all bird-related papers from the resulting output and used their cited literature to find other papers not captured by our search criteria. This approach did not provide a comprehensive list of studies that used video technology because these databases only index titles, keywords, and abstracts, whereas in many cases the use of video technology is first mentioned when methods are presented. Nevertheless, our approach provided us with an ample number of papers for this review. We noted whether the study used analog (i.e., VCR) or digital recording units; the method of recording [e.g., still photos, real-time ( $\geq 25$ frames per sec) or time-lapse ( $<25$ frames per sec) video, 24-hr (continuous) or subsampled hours, with or without triggering mechanism]; and the source of equipment [i.e., vendor-built (professionally designed and constructed) or user-built (at least partially designed and constructed by the researcher)]. We assumed that papers using camera systems more complex than a simple hand-held recorder would provide vendor information when applicable. We also recorded whether the camera system was used with artificial or real nests, and in the latter case we recorded the focal species studied. Finally, we recorded the stated objective(s) for each study. In many papers we could not adequately determine some of the information we were seeking, so sample sizes for summary statistics presented below are variable.

\section{Case Studies}

In 2007-2009 we designed and tested two userbuilt digital video monitoring systems (referred to as System One and System Two when necessary hereafter; see Table 15.1 for a detailed list of components). Both systems consisted of a miniature digital video recorder (DVR), a battery, and a BNC power/video extension cable $(10-30 \mathrm{~m})$ that connected the recorder to a weatherproof, day/night security camera (Fig. 15.1). System One included a voltage converter because the DVR and camera operated at different voltages. We housed the recorder, voltage converter, and battery in either a waterproof Pelican ${ }^{\mathrm{TM}} 1500$ case or a camouflaged 18-30 gallon plastic container.

We used six different fixed-focus camera models that ranged from $\$ 30$ to $\$ 170$ (USD). All 
TABLE 15.1

List of major components and their costs (USD) for two user-built digital video systems designed for nest predator identification studies.

\begin{tabular}{|c|c|c|c|c|}
\hline Component & System One & Cost & System Two & Cost \\
\hline DVR & $\begin{array}{l}\text { Yoko Tech } \\
\text { RYK9122 }\end{array}$ & $\$ 190$ & Seorim AKR-100 & $\$ 150$ \\
\hline Camera & $\begin{array}{l}\text { Rainbow CCTV } \\
\text { BB22WIRC** }\end{array}$ & $\$ 160$ & $\begin{array}{l}\text { Supercircuits } \\
\text { PC6EX-3* } \\
\text { Supercircuits } \\
\text { PC6EX-4 } \\
\text { Supercircuits } \\
\text { PC331-IR } \\
\text { Supercircuits } \\
\text { PC506-IR } \\
\text { Supercircuits } \\
\text { PC168-IR }\end{array}$ & $\begin{array}{l}\$ 30 \\
\$ 50 \\
\$ 70 \\
\$ 90 \\
\$ 90\end{array}$ \\
\hline Voltage converter & $\begin{array}{l}\text { ESCO-Ohio } \\
\text { 3-terminal }\end{array}$ & $\$ 20$ & & \\
\hline Waterproof case & Pelican $^{\mathrm{TM}} 1500$ & $\$ 70$ & plastic containers & $\$ 3, \$ 10$ \\
\hline Video/power cable & $15 \mathrm{~m} \mathrm{BNC}$ & $\$ 20$ & $30 \mathrm{~m} \mathrm{BNC}$ & $\$ 25$ \\
\hline Battery & $\begin{array}{l}\text { Sealed lead-acid } \\
\text { Werker WKA112-26NB }\end{array}$ & $\$ 85$ & deep-cycle (various) & $\$ 60-80$ \\
\hline Battery charger & Schumaker SC-600A & $\$ 40$ & various & $\$ 25-60$ \\
\hline Memory cards & Various (4GB) & $\$ 10$ & various (8GB) & $\$ 20$ \\
\hline Portable monitor & Supercircuits MON-1 & $\$ 100$ & various & $\$ 80-435$ \\
\hline
\end{tabular}

NOTES: Camera models recorded color images except those marked with an asterisk (*), which recorded monochrome images.

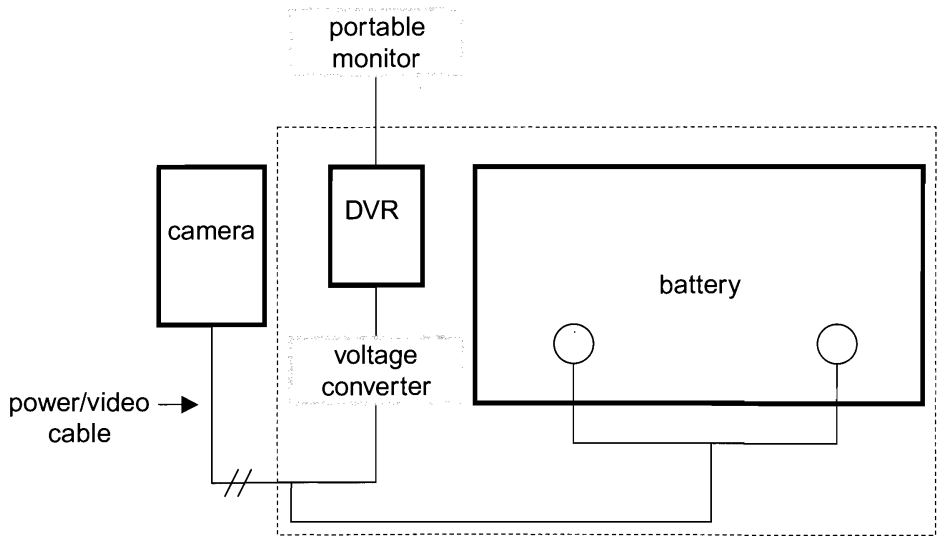

Figure 15.1. Schematic of a user-built digital video recording (DVR) system. The dashed line surrounds components housed in a waterproof case. Components in gray boxes may not be required; some DVR models have integrated liquid crystal displays and some may operate at the same voltage as the camera (typically 12 volts). 
but the two least expensive models were weatherproof; we sealed the latter models with a plastic coating and housed them within a PVC cap to prevent moisture penetration. For nighttime illumination, the most expensive model was equipped with infrared (IR) light-emitting diodes (LEDs) that emitted light at a peak wavelength of $940 \mathrm{~nm}$; the rest had LEDs with a peak wavelength of $850 \mathrm{~nm}$. We had the vendor replace the wide-angle $3.6-\mathrm{mm}$ lens with a $12-\mathrm{mm}$ lens on the most expensive model, which allowed for camera placement at greater distances from nests. The lenses on the remaining five models ranged from 3.6 to $8 \mathrm{~mm}$. We used paint, natural vegetation, and/or tree bark to improve camera concealment.

We used two different DVR models. The DVR for System One allowed for three resolution settings up to $704 \times 480$ (vertical $\times$ horizontal lines), while System Two's DVR only recorded at a low resolution $(352 \times 240)$. Image compression rate options (i.e., the amount of detail stored per frame) provided three different recording qualities, and the number of frames recorded per second (fps) ranged from 1 to 30 . Time and date stamps could also be added to the video. Images were stored on 4-8-GB SD or SDHC memory cards (not supplied with the DVR). The typical duration of a recording period was $2-4 \mathrm{~d}$ and was dependent upon the settings we chose (usually $6 \mathrm{fps}$ of normal or high-quality video at the lowest resolution) and the memory card capacity. However, both DVRs used a memory-saving algorithm which resulted in differing memory requirements for each nest (i.e., the number of hours of video that could be recorded differed based on camera field of view, amount of movement within the field of view, etc.), so we would adjust settings in the field as needed. Both DVRs also had a motion-detection feature that could save substantial storage space (see discussion), but we did not test this option.

We powered each unit with a single deep-cycle marine battery (75-125 amp hr) or a sealed leadacid battery (26 amp hr). The total cost per system, including SD cards, batteries, chargers, and a small digital monitor for confirming system function and checking camera alignment ranged from $\$ 350$ to $\$ 725$ per unit when multiple units are purchased (if cameras are tended to on alternating days, two units can share a battery charger, replacement batteries, and SD cards).
We tested our video systems in 2007-2009 at field sites in Missouri, Illinois, and Arkansas. In Missouri and Illinois, we deployed cameras at passerine nests in shrublands and forests. We typically placed cameras 1-4 m from nests, mounted on a tripod or wooden dowel, attached to thin $(\sim 1-4 \mathrm{~cm})$ branches with a spring-loaded metal clip, or affixed to a tree trunk with brown duct tape or with a custom-made cargo strap. In Arkansas, we deployed cameras at Mississippi Kite (Ictinia mississippiensis) nests. Because these nests may be located $>30 \mathrm{~m}$ above the ground, we sometimes joined multiple 30-m BNC cables using female-female BNC couplers prior to climbing to the nest. The camera was attached to the limb of the nest tree, $0.4-0.5 \mathrm{~m}$ above the nest, using camouflaged plastic cable ties. For all mounting methods, we sprayed the extension cable and exposed camera wires with Ropel ${ }^{\circledR}$, a nontoxic chemical, to deter wildlife from damaging them. We camouflaged all components of the system with small branches, leaves, and other vegetation to prevent predators from being affected by the equipment (Herranz et al. 2002, Richardson et al. 2009) and to maximize the likelihood of nesting birds accepting the camera. We placed the waterproof case $8-10 \mathrm{~m}$ from passerine nests and approximately $30 \mathrm{~m}$ from raptor nests to minimize disturbance to the nesting bird when changing the battery and memory card. The total time for camera setup was generally $\leq 15 \mathrm{~min}$ for one person at passerine nests and $\sim 1 \mathrm{hr}$ for two people at raptor nests.

Once out of the field, we downloaded data from the SD cards to an external hard drive using a standard SD card reader. The more expensive DVR broke the total time recorded into separate 1-MB files. This resulted in thousands of files for a 48-hr recording period, but it also allowed for easy manipulation of files (e.g., sections of video were easily deleted or stored in separate places). The files were in MPEG-4 format, which is compatible with many freely available media players, but we chose to use Windows Media Player 11 because it allows multiple files to be queued for sequential play. The other DVR stored files in 30-min increments in a proprietary format that required special software to view, but those files could also be converted to a commonly used file format for viewing on most players. 


\section{RESULTS}

\section{Literature Review}

We found 327 journal articles that mentioned use of photo or video technology (Table 15.2), the frequency of which increased over time (Fig. 15.2; see Appendix 15.1 for a complete list of articles). Three primary types of recording equipment were used. Systems that record in real time ( $\geq 25 \mathrm{fps}$ ) were used regularly ( $27 \%$ of all publications), but most of these did not continuously record data at nests $24 \mathrm{hr}$ per day (e.g., many recorded 2- or 4-hr samples). Time-lapse video systems, which record at $<25 \mathrm{fps}$, were most common (38\%). Systems with manual or IR triggers that took still photos of nests were also common (33\%). Less commonly used were video systems that did not record images $(8 \%$; usually associated with checking nest contents). Digital technology was used in $11 \%$ of studies since its first use in 2003 and in $21 \%$ of studies since 2006 .

Twenty percent of these systems were built by vendors and $11 \%$ were unmodified handheld video cameras. The remaining $69 \%$ of systems required some assembly by the end user. The user-built video systems varied greatly in sophistication and purpose. Nest-checking equipment included cameras designed to allow access to nests of canopy, cavity, or burrow-nesting species that would otherwise be unreachable (e.g., Dyer and Hill 1991, Proudfoot 1996). Systems for monitoring adult behavior were often simple modifications of hand-held camcorders (e.g., Honza and Moskát 2008) but also included some impressive uses of wireless (King et al. 2001), solar (e.g., Margalida et al. 2006), and satellite (e.g., Momose et al. 2003) technologies.

The studies using camera technology recorded data for 255 species from 19 orders. We identified eight broad categories that encompassed most papers' study objectives (Table 15.2). Cameras were most commonly used to identify nest predators, but they also were frequently used in studies of adult and nestling behavior, especially related to feeding ecology. Many papers presented user-built video systems, including systems used to identify the contents of otherwise inaccessible nests. Studies reporting extra-pair adults (conspecific and otherwise) that visited the nest were less common. Finally, a small number of studies evaluated the impact or efficacy of video cameras or other technology (e.g., radio transmitters) at avian nests.

TABLE 15.2

Number of studies published during 1956-January 2009 that used camera technology (see Appendix 15.1), listed by study objective and type of recording technology used.

\begin{tabular}{lcccc}
\hline & \multicolumn{2}{c}{ \% of studies in category } \\
\cline { 2 - 5 } Study category & No. studies & Still & Time-lapse & Real-time \\
\hline Nest predator identification & 114 & 50 & 43 & 6 \\
Feeding ecology & 103 & 28 & 32 & 40 \\
Adult behavior & 81 & 6 & 45 & 43 \\
Present a user-built system & 32 & 39 & 35 & 26 \\
Nest contents identification & 23 & & 21 & 79 \\
Nestling behavior & 19 & 0 & 58 & 17 \\
Camera or technique evaluation & 15 & 25 & 45 & 55 \\
Intruder behavior & 13 & 0 & 60 & 40 \\
Other & 7 & 0 & & \\
\hline
\end{tabular}

NOTES: Studies that had multiple objectives are included in more than one category. When calculating percentages, we excluded systems that were not adequately described or did not have a recording unit. Mechanical or infrared triggers were used in all but one still-frame system, which used digiscoped photos. Triggers were used in $4 \%$ of time-lapse systems and $12 \%$ of systems that provided real-time ( $\geq 25 \mathrm{fps}$ ) video. Feeding ecology studies include studies on provisioning rates, food loads, and prey identification. Adult behavior studies include studies on nest defense by parent birds and helpers in cooperatively breeding species and on breeding behavior other than feeding (e.g., nest attentiveness). With one exception (Hudson and Bird 2006), systems used to check nest contents relayed images to a video screen but did not record them. Intruder behavior studies include studies on brood parasites and conspecific adults of non-cooperatively breeding species. 


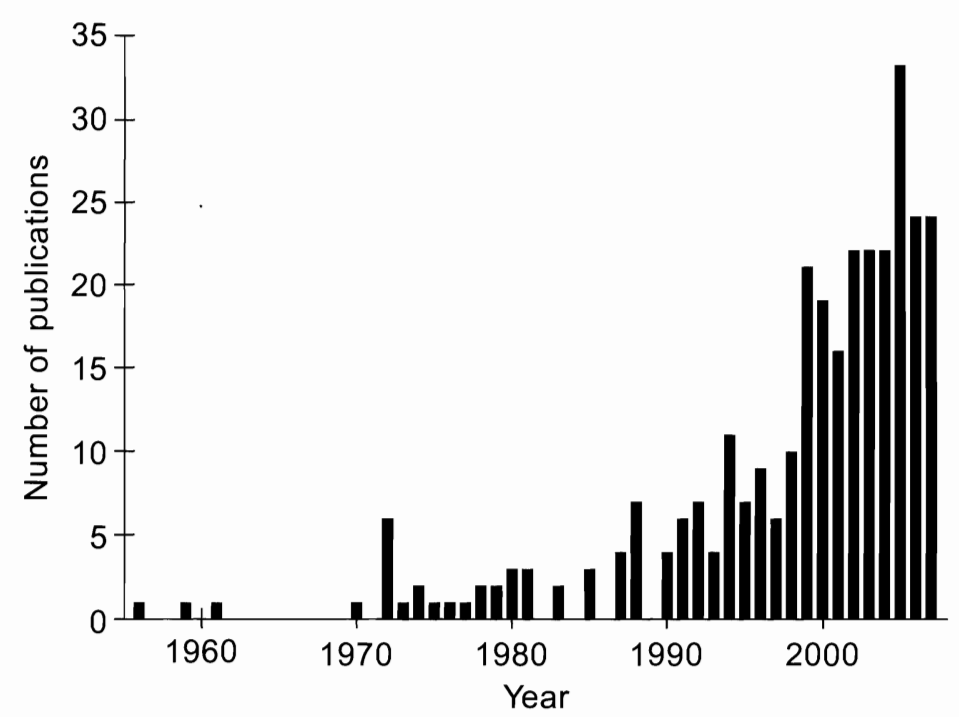

Figure 15.2. Camera technology has been used with increasing frequency between 1956 and 2007, the last year in which papers were fully indexed when we performed our literature search.

\section{Case Studies}

We obtained video footage at 125 nests of ten species and determined the cause of failure at 53 of 66 unsuccessful nests with System One. At one nest, the female disappeared $9 \mathrm{~d}$ after camera setup, but the extended period between camera installation and the female's disappearance suggests the abandonment was not caused by our activities. At two nests we were not able to identify a predator even though the camera was functioning correctly. We removed cameras at four nests prior to nest failure, and we failed to record predation events at seven nests because of technician error $(n=3)$, video system malfunction $(n=3)$, or because a camera fell $(n=1)$. In all other cases, predators were identified to guild (e.g., raptor, mouse, snake). Although many images were clear (Fig. 15.3A), poor video quality associated with the distance between the nest and the camera (i.e., cameras too close to nests were out of focus and those that were too far had insufficient detail to identify small predators) prevented species identification of 16 of $50(31 \%)$ of the recorded predators (Fig. 15.3B). In 2009, we tested a color camera with manual focus and zoom controls to alleviate this problem, but image quality was generally worse (Fig. 15.3C). Predators not identified to species included all rodents $(n=7)$, five of 22 raptors, and four of seven snakes.
We obtained video footage at 53 nests of nine passerine species using System Two and determined the cause of failure at 27 of 29 failed nests. Image quality was generally quite good (Fig. 15.3D) and we were able to identify all predators except for one mammal to species. In Arkansas, we collected video data from six Mississippi Kite nests. We recorded one predation event by a Texas ratsnake (Pantherophis obsoletus; formerly black ratsnake, Elaphe obsoleta) and documented a nonpredator-related failure caused by a severe thunderstorm that degraded the nest, causing the egg to fall through it while the adult was incubating.

System One's reliability was lower than expected in 2007. We failed to record data on 121.5 of $758 \mathrm{~d}$ ( $16 \%$ failure rate). Of all causes of system failure, the most frequent were a DVR firmware malfunction that prevented the download of files (64\% of failure days) and faulty wiring between the battery and the recorder $(10 \%)$. We installed a firmware upgrade from the DVR manufacturer prior to the 2008 season and the reliability of our systems improved; we failed to record data on 51 of 928 d ( $6 \%$ failure rate). However, our voltage converters did not function as expected and several DVRs began to perform erratically or fail completely ( $30 \%$ of all failure days). The second video system generally performed reliably; we only failed to record data on 32 of $743 \mathrm{~d}$ in the field (4\% failure rate) and did not have any notable 

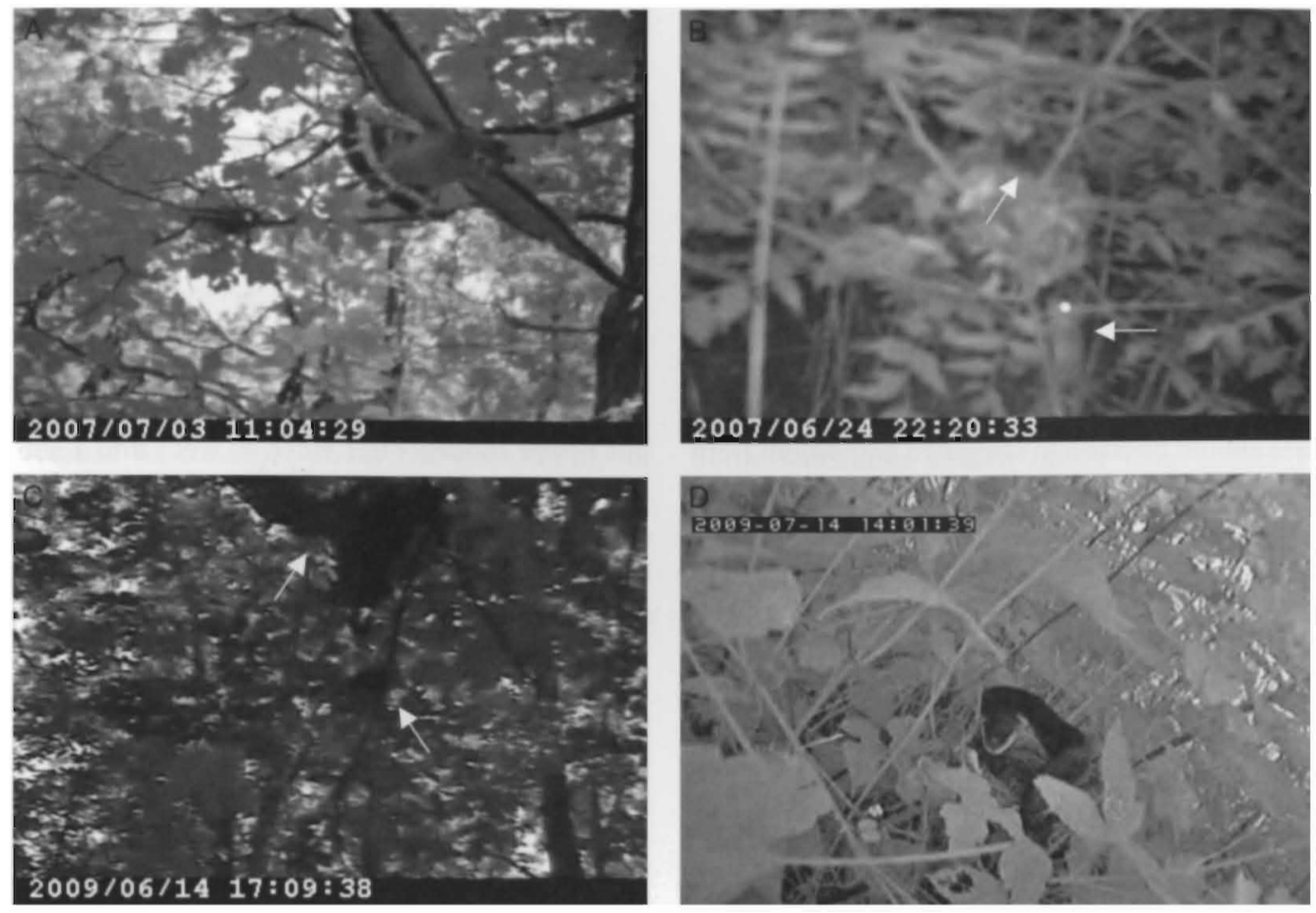

Figure 15.3. Sample images from our case studies. (A) a Broad-winged Hawk (Buteo platypterus) depredates an Acadian Flycatcher nest. The same fixed-focus camera provided lower-quality images when placed closer to a nest (B). The video was out of focus in the day and worse at night; the Indigo Bunting (B, top arrow) is barely visible, and the mouse (bottom arrow) cannot be identified to species. Some camera models rarely provided good images; the camera that recorded the image of a hawk (C, top arrow) depredating an Acadian Flycatcher nest (bottom arrow) usually produced pixelated images with poor contrast despite the fact that it had manual focus and zoom controls. In contrast, the fixed-focus model used to record the Texas ratsnake (D) typically provided high-quality color images.

technical problems. Causes of failure common to both systems include: exceeding the capacity of memory cards prior to the end of the recording period $(8 \%$ of combined failure days for both systems), power failure when batteries died prematurely (7\%), and rodents chewing through wiring (6\%).

\section{DISCUSSION}

Video systems are being used with increasing frequency because they facilitate efficient collection of data on many aspects of avian reproductive biology that would otherwise be impractical or impossible to obtain. Their use across a broad array of avian taxa and study objectives demonstrates their wide range of utility but also indicates that there is no single ideal system. As such, it can be difficult to determine what kind of system is optimal for a particular study. Our literature review and experience in the field suggest that careful consideration of one's study objectives combined with an understanding of the components of commonly used video systems are needed to choose the right system. Although we cannot offer advice related to study objectives, we believe the following guide can help researchers understand the basic technology involved in most video systems used to monitor bird nests.

\section{Image-recording Units \\ Camcorders, Trail Cameras, and \\ Still-frame Cameras}

The first question researchers should ask is whether off-the-shelf equipment will suffice to meet their study objectives. These are often the least expensive, least time-consuming options (hand-held camcorders, trail cameras, still-frame 
cameras) and do not require separate camera and recording components. Clearly, commercially available video cameras that record in real time for relatively short durations are not desirable for nest predation studies, but their relatively low cost (many models are available for $<\$ 300$ ) and ease of use make them well suited for behavioral studies where subsampled time periods are standardized among nests (e.g., food-provisioning or incubation behavior). These cameras, however, are generally not designed for prolonged outdoor use, and measures should be taken to safeguard equipment from adverse field conditions.

Still-frame cameras have been used primarily for nest predator identification and feeding ecology studies (the latter almost exclusively with cavity-nesting species). For both study objectives, researchers have typically used systems that only record images when a mechanical or IR trigger is tripped (reviewed in Reif and Tornberg 2006). Mechanical triggers coupled with still-frame cameras are now used primarily in conjunction with artificial nests to identify nest predators $(79 \%$ of studies from 1990 to 2007), but such use may not be warranted. In addition to the biases associated with artificial nests (Buler and Hamilton 2000, Thompson and Burhans 2004), camera shutter sounds can disrupt predation events and single images (many still-frame models cannot take rapid successive photos) may not provide conclusive evidence of a predation event (Pietz and Granfors 2000). Further, even when used at real nests, still-frame cameras and mechanical triggers may systematically undersample certain predator guilds during the nestling stage (Liebezeit and George 2003).

IR triggers can be active (a transmitter emits an IR beam to a receiver placed on the opposite side of the nest) or passive (a receiver detects changes in radiant IR levels). Active triggers take longer to set up and may not perform as well as passive ones (Bolton et al. 2007), but researchers have experienced problems with passive triggers as well (Hernandez et al. 1997). For example, passive triggers may be activated by abiotic factors such as temperature and/or sunlight changes, and they may not be sensitive to the movement of small animals (Brown and Gehrt 2009). Both passive and active IR triggers used with either camcorders or still-frame cameras are external to the recording device, which results in a pause (typically $\leq 0.5 \mathrm{sec}$ ) between motion detection and camera activation.
The newest triggers can have very short pauses $(\leq 0.15 \mathrm{sec})$ that minimize the risk of lost data. Nevertheless, in some study systems certain events [nest predation by ants (Stake and Cimprich 2003, Connor et al. 2010) or harvestmen (Benson et al. 2010)] may not activate triggers, while in other cases they may be frequently activated by non-targeted events such as moving vegetation.

Trail cameras, such as those used by hunters to identify game animals, usually integrate passive IR triggers and cameras (typically still-frame, but newer models offer video as well) into a single unit and are explicitly designed for extended deployment in the field. They are more energy efficient than systems that record continuously, so most models run off household batteries. Many models are larger than cameras used in other nest monitoring systems and are usually equipped with wide-angle lenses; these factors make them impractical for some species, but they may be cost effective, off-the-shelf tools for recording images at nests of larger species (Dreilbelbis et al. 2008). The newest, most expensive models are more compact and have been used at passerine nests, but even those placed within $1 \mathrm{~m}$ of the nest did not capture all predation events because the IR trigger sometimes failed to detect movement at the nest (G. Londoño, pers. comm.).

\section{Digital Recorders}

While systems that record continuously for extended durations may be too expensive and unneeded for many study objectives, they are usually necessary for identifying nest predators. Rapid advances in digital technology have resulted in the production of sophisticated DVRs and highcapacity flash memory, which allow for the capture and storage of high-quality digital video. These devices can be integrated by vendors or end users into video monitoring systems like those used in our case studies. Digital equipment is lighter, more reliable, less expensive, and uses less power than comparable analog components that were commonly used in the past; we see little reason for researchers to consider analog equipment.

There is a variety of DVRs available in the marketplace suitable for monitoring bird nests. The models we used in our case studies were small (both DVRs we used were $\leq 6 \times 9 \times 2 \mathrm{~cm}$ ) and offered a number of options (e.g., resolution, frame rate, video quality) often found in other 
models as well. One feature we did not test was the integrated passive triggers (i.e., motion detection recording options) that eliminate the pause between the trigger and camera activation previously described by including $0.5 \mathrm{sec}$ of video prior to activation of the trigger. This kind of trigger was tested by Bolton et al. (2007), was successfully used in several subsequent studies (Morris and Gilroy 2008, Stevens 2008), and can drastically reduce memory usage. Regardless, we chose not to use the motion detection options of our DVRs because of concerns about the detectability of some predators.

Several options our DVRs lacked may be useful to other researchers. First, many portable DVRs have integrated hard disk drives, which offer greater storage capacity than the SD cards we used with our DVRs. These DVRs can significantly extend deployment periods or allow researchers to gather higher-quality video (i.e., increased resolution or frame rate). However, downloading the data from the DVR in the field can be time consuming and may require a laptop or extra DVRs to replace those with full hard drives (Pierce and Pobprasert 2007). Second, our DVRs required a small portable monitor to view the recording settings, but other models have integrated liquid crystal displays (LCDs), which eliminate the need for an external monitor. Portable monitors are relatively inexpensive and have other uses as well (see below), so integrated LCDs may not be worth the extra cost for some researchers. Finally, for study systems with high nest densities, multi-channel DVRs allow researchers to simultaneously record video from multiple nests (Colombelli-Négrel et al. 2009).

\section{Cameras for Use with DVRs}

Many types of cameras can be effectively deployed at nests, but the most useful types are likely those designed for security applications. A major advantage of these cameras is that many are designed for outdoor use and are therefore able to withstand extreme temperatures and precipitation, and most are designed to use a $12-\mathrm{V}$ DC power source. Depending on the features included, these cameras vary greatly in size and in the power they consume. Price also tends to vary with the features included, but many field-worthy cameras are available for $<\$ 150$. Cameras offer different levels of resolution (described by the number of horizontal lines that compose a frame, also called TVL), but researchers will only benefit from increased camera resolution if they are also recording in high resolution. For example, if a DVR is recording at low resolution $(352 \times 240)$, then images from all cameras with $\geq 240$ TVL will have the same resolution when played back.

Cameras come with or without IR LEDs for night recording; models that provide nighttime illumination have variable effective ranges depending upon the type and number of LEDs. Some substrates absorb rather than reflect IR light, which can result in an effective range that is smaller than that specified by the camera manufacturer (Sabine et al. 2005). Separate IR illuminators can also be used to provide additional light for night recording, but these can only be used with cameras that have lenses sensitive to infrared light. An important consideration when choosing an IR illuminator or camera is the wavelength of light emitted by its LEDs. LEDs with shorter $(850 \mathrm{~nm})$ versus longer $(940 \mathrm{~nm})$ peak wavelengths tend to provide better lighting in near to total darkness and are much more commonly available, but they emit some light in the visible spectrum, which appears to humans as a faint red glow; LEDs with longer peak wavelengths emit light that is invisible to humans. The glow is only visible from a relatively narrow range of viewing angles and does not seem to affect predation rates (Sanders and Maloney 2002, this study's AR and IL data), but to our knowledge no studies have explicitly investigated its influence on predator behavior.

The focal length of camera lenses should also be taken into account when choosing a camera. Those with wide-angle lenses have shorter focal lengths, requiring them to be relatively closer to nests, but because cameras with wide-angle lenses remain focused at variable distances, the distance from camera to nest does not need to be exact to preserve picture quality. Lenses with longer focal lengths, on the other hand, can be situated farther from nests because they provide greater magnification, but they need to be placed at a more precise distance from the nest to avoid reduced picture quality. Our experience suggests that cameras with relatively wide-angle lenses ( $\leq 8 \mathrm{~mm}$ focal length) work well when cameras can be placed close (e.g., $\leq 2 \mathrm{~m}$ ) to nests. We used a camera with a longer focal length $(12 \mathrm{~mm})$ to film Acadian Flycatchers because their nest placement 
generally did not allow for cameras to be closer than $3 \mathrm{~m}$. We recently disassembled two different fixed-focus camera models and found that adjusting the focal point of the lens can be done rapidly and easily, so we plan to do this during setup at nests in future years. However, we must caution that IR LEDs are matched with lenses to provide optimal lighting at specific distances, so adjusting or replacing lenses may reduce nighttime image quality. Many newer models offer variable zoom and focus options which can improve the flexibility of camera setup and placement without such a sacrifice, as the LEDs are configured to match the variable focal distances of the camera. However, even though the 940-nm camera we tested in 2009 had a $9-22-\mathrm{mm}$ zoom color lens and manual focus controls, it did not operate well during the day in low light and image quality was very poor in heavily shaded habitats or at dusk and dawn.

Color cameras will be necessary for researchers recording marked birds, and many of our color models performed quite well. But color images require more memory than black-and-white images, and our experience suggests that with some models colors can appear dull or washed out even when lighting is good, which limits their use for identifying color-banded birds. Our conversations with vendors suggest that in general, black-and-white cameras tend to produce sharper, less pixelated images, especially in cameras equipped with 940-nm LEDs.

Recent advances in IR LEDs should result in cameras that provide brighter images at greater distances more efficiently than current models, and new lenses are being developed that provide increased clarity in IR-illuminated images. Other new technologies that may improve cameras for avian nest studies include digital noise reduction (DNR) and wide-dynamic-range (WDR) cameras, both of which are intended to improve image quality and reduce pixelation in low light conditions. Furthermore, new cameras are commercially available that amplify ambient light and do not require IR LEDs when recording at night, although we have not tested these. Regardless of the model chosen, we recommend that researchers test it under normal field conditions prior to purchasing in quantity or relying on it for highquality data collection. Security cameras are not designed specifically for wildlife studies, and not all models will perform as desired. For example, some of our cameras did not function well unless placed near enough to a nest for it to occupy a substantial portion of the field of view, which was not always possible. Furthermore, some species are much more sensitive than others to the presence of cameras and may require special models; adults at three Kentucky Warbler (Oporornis formosus) nests would not accept camouflaged cameras even when placed 4-5 $\mathrm{m}$ from the nest (W. Cox, pers. obs.).

\section{Other Technical Considerations}

Most of the video systems we found in the literature were powered by traditional lead-acid batteries. Deep-cycle marine batteries are cost effective and typically have high charge capacities but are relatively heavy $(23-30 \mathrm{~kg})$; sealed lead-acid batteries can be significantly lighter and are safer (there is little danger of acid burns) but are also more expensive. Lithium batteries are much more expensive than their lead-acid counterparts but are an effective way to drastically reduce the size and weight of a video system. Batteries have variable life spans, but many can be used for five field seasons or more. To maximize life span, batteries of all types should be charged at a low amperage (e.g., 2-6 amps) and should be charged periodically when not in use for extended periods. Solar panels have been used frequently over the past decade, and when combined with wireless transmitting technology they offer an ideal solution for researchers working in remote areas or with species whose nests are difficult to access (Margalida et al. 2006). Fuel cells are another expensive but useful power option for researchers lacking frequent access to nests and/or a power grid (www. sandpipertech.com/remote_power.html).

Cables and connectors are also required in most systems to provide power to the components and transmit the video data to the recorder. The distance between the camera and its associated recording equipment and power supply should be great enough to allow researchers to download data and exchange batteries without flushing adult birds from the nest or inciting alarm calls from adults attending nestlings. Cables can be purchased in varying lengths or connected in series to allow the recording equipment to be placed far from the nest without noticeable signal degradation. Although separate power and video cables can be purchased, cables that combine both functions are commercially 
available, generally sturdy enough for field use, and relatively inexpensive. In addition to these cables, connectors that convert between RCA and BNC plug types are generally needed, and short connectors with alligator clips that facilitate attachment to the battery are also useful; these are available from several sources including stores that sell electronics components. To prevent damage to the video/power cable, primarily by gnawing mammals, chemical deterrents are available (Ropel ${ }^{\circledR}$ ) but do not always work. Other researchers have wrapped cables in aluminum tape (Booms and Fuller 2003) or buried them (Coates et al. 2008) to reduce the risk of damage. In areas where rodent damage was severe, we handled our cables with rubber gloves to reduce scent and mineral deposition and we concealed metal connectors with electric tape to prevent their theft by wood rats (Neotoma spp.). However, even with these deterrents occasional cable damage is likely inevitable, and researchers should purchase spare cables to prepare for this possibility. Some researchers (Pechacek 2005, King and DeGraaf 2006) have used wireless technology instead of cables to connect a camera to a DVR (reviewed in Reif and Tornberg 2006). This eliminates the risk of cable damage from rodents and allows for the study of nests that are difficult to access (Margalida et al. 2006), though a separate power source for the camera and transmitter is required and systems may require line-of-sight between transmitting and receiving antennas.

A portable LCD viewing monitor is necessary for some DVRs and can be helpful during setup and nest checks for most systems. Monitors can be connected directly to a camera, which allows for efficient and exact camera placement. For DVR models without video screens, monitors are required to ensure proper camera placement, to view DVR menu options when changing recording settings (e.g., fps, resolution, picture quality), and to check the remaining memory on cards.

Finally, some recent video systems have integrated computers which help researchers control and store data. Colombelli-Négrel et al. (2009) designed a system that used a computer to manage data from multiple video and audio recorders, while Grivas et al. (2009) constructed a wireless video/audio monitoring system that had a local computer receive, record, and transmit data to a remote computer ( $145 \mathrm{~km}$ from the nest) from which researchers could control the system.

\section{User- Versus Vendor-built Systems}

For those who require a system more specialized than what is available off the shelf, an important consideration is whether to build their own or purchase one from a vendor. The majority of video systems used in the reviewed papers were at least partially user-built. Relative to vendor-built systems, a primary advantage of user-built systems is lower cost. For example, our systems cost approximately $\$ 350-725$ per unit, which is significantly less than comparable vendor-built units (System One cost $\sim 33 \%$ of a comparable vendorbuilt unit at the time it was constructed in 2007). Repair costs are typically less expensive as well, as no labor charges or markups on components occur. Other researchers presenting user-built systems noted similar savings (King et al. 2001, Hudson and Bird 2006). These savings are especially pertinent for researchers using cameras to identify nest predators because sample sizes are often small and constrained by the number of cameras available.

A user-built video system may not be the best choice for all biologists. Considerable time and effort went into manufacturing each system, and our initial experiences with System One were not wholly positive. We were unable to address image-quality issues associated with our fixedfocus cameras because we did not have the expertise to build a camera that fit our exact specifications and none were available commercially (most IR cameras have a peak wavelength of $850 \mathrm{~nm}$ ). Furthermore, the reliability problems associated with our DVR and voltage converter were not easily diagnosed and resulted in the loss of data. Finally, our system lacks reverse polarity protection, so operator error can result in catastrophic failure of some system components. By contrast, vendor-built systems may offer greater reliability and more flexibility in system design, and do not require the user to diagnose and repair malfunctioning equipment.

We cannot make an unambiguous recommendation as to whether researchers should use vendor- or user-built video systems. Vendor-built systems are often relatively expensive, and repairing them may not be possible in the field. But they can also offer researchers greater ease, reliability, and technical sophistication. User-built systems are much cheaper but require more knowledge, time, and effort to build. For researchers who 
do wish to explore building their own systems, we first recommend that they consult the literature (including this study) to learn what, if any, systems have been designed and used for their species and/or study objective. There are many good examples of video systems in the literature that can provide excellent guidance on general system design despite the fact that the rapid pace of technological developments makes many past systems functionally obsolete. We also think that researchers who custom-build a video system may benefit by consulting someone with electronics experience who can help identify potential pitfalls in design and component selection. In 2009, for example, we purchased inexpensive, professionally constructed voltage converters (ESCO-Ohio. com) to replace the problematic ones in our first case study; this fully resolved our problems with DVR failure (W. Cox, unpubl. data).

\section{Final Thoughts}

Miniaturized cameras coupled with digital recording and data storage are changing how we approach the study of avian reproductive ecology. The amount and quality of data that can be collected in a season with even a few well-placed cameras far exceeds what was previously possible with systematic or opportunistic observation by human observers. Furthermore, for some study objectives, cameras have demonstrated that older methods of data collection were either unreliable (Thompson and Burhans 2003) or heavily biased (Thompson and Burhans 2004). Video is not a bias-free panacea; nests monitored with cameras may have lower predation rates than those without cameras (Richardson et al. 2009) and care must be taken to minimize any effects on nesting birds or their predators. Regardless, video systems offer the promise of large volumes of high-quality data and are increasingly being used by ecologists to document and quantify events and behaviors that are difficult or impossible to observe directly. The study species and objectives will largely dictate specific needs, but the availability of funds for purchasing and maintaining multiple systems is a constraint for most studies. Once a system has been chosen, field tests are critical for assessing functionality, identifying potential problems, and developing protocols to troubleshoot those problems (e.g., availability of extra parts or on-site expertise).
The use of stationary cameras to monitor nests is a well-established practice, but we are now reaching a degree of technological sophistication that will no longer restrict researchers to a stationary observation site. Perhaps the most exciting recent use of video is that of Rutz et al. (2007), who attached miniature cameras to New Caledonian Crows (Corvus moneduloides) to collect data on foraging behavior and tool use. These tiny cameras were combined with VHF radio transmitters, allowing the researchers to couple finescale foraging data with larger-scale spatial data. Given the accelerated rate of microcircuitry miniaturization, researchers may be able to obtain similar video images from all but the smallest of avian species in the near future.

\section{ACKNOWLEDGMENTS}

We thank the many assistants who helped maintain the cameras in the field, as well as the Missouri Department of Conservation for providing housing. We also thank the private land owners who granted us access to their property. We thank M. Ward, M. Alessi, H. Fraser, and D. Barron of INHS, and the Vermilion County Conservation District, particularly M. Pittman and K. Konsis, for assistance with the research in Illinois. We thank staff at the White River National Wildlife Refuge for logistical support. We thank P. J. Pietz, A. J. Pierce, and K. Sullivan for their reviews of this manuscript; their efforts greatly improved its quality. We thank the USDA Forest Service, the Audubon Society of Missouri, the Trans-World Airlines Scholarship program, the Illinois Department of Natural Resources, the Illinois Natural History Survey (INHS), the Arkansas Game and Fish Commission, and the U.S. Fish and Wildlife Service for funding the fieldwork for this project.

\section{LITERATURE CITED}

Ben-Dov, A., Y. Vortman, and A. Lotem. 2006. First documentation of sibling cannibalism in a small passerine species. Ibis 148:365-367.

Benson, T. J., J. D. Brown, and J. C. Bednarz. 2010. Identifying predators clarifies predictors of nest success in a temperate passerine. Journal of Animal Ecology 79:225-234.

Bolton, M., N. Butcher, F. Sharpe, D. Stevens, and G. Fisher. 2007. Remote monitoring of nests using digital camera technology. Journal of Field Ornithology 78:213-220.

Booms, T. L., and M. R. Fuller. 2003. Time-lapse video system used to study nesting Gyrfalcons. Journal of Field Ornithology 74:416-422. 
Brown, J., and S.D. Gehrt. 2009. The basics of using remote cameras to monitor wildlife. Ohio State University Extension Agriculture and Natural Resources Fact Sheet W-21-09. Ohio Sate University, Columbus, $\mathrm{OH}$.

Buler, J. J., and R. B. Hamilton. 2000. Predation of natural and artificial nests in a southern pine forest. Auk 117:739-747.

Cartar, R. V., and R. D. Montgomerie. 1987. Day-today variation in nest attentiveness of White-rumped Sandpipers. Condor 89:252-260.

Coates, P. S., J. W. Connelly, and D. J. Delehanty. 2008. Predators of Greater Sage-Grouse nests identified by video monitoring. Journal of Field Ornithology 79:421-428.

Colombelli-Négrel, D., J. Robertson, and S. Kleindorfer. 2009. A new audio-visual technique for effectively monitoring nest predation and the behaviour of nesting birds. Emu 109:83-88.

Conner, L. M., J. C. Rutledge, and L. L. Smith. 2010. Effects of mesopredators on nest survival of shrubnesting songbirds. Journal of Wildlife Management 74:73-80.

Cutler, T. L., and D. E. Swann. 1999. Using remote photography in wildlife ecology: a review. Wildlife Society Bulletin 27:571-581.

Dreibelbis, J. Z., K. B. Melton, R. Aguirre, B. A. Collier, J. Hardin, N. J. Silvy, and M. J. Peterson. 2008. Predation of Rio Grande Wild Turkey nests on the Edwards Plateau, Texas. Wilson Journal of Ornithology 120:906-910.

Dyer, P. K., and G. J. E. Hill. 1991. A solution to the problem of determining the occupancy status of Wedge-tailed Shearwater Puffinus pacificus burrows. Emu 91:20-25.

Gilbert, W. M., P. M. Nolan, A. M. Stoehr, and G. E. Hill. 2005. Filial cannibalism at a House Finch nest. Wilson Bulletin 117:413-415.

Grivas, C., S. M. Xirouchakis, C. Christodoulou, B. Carcamo-Aboitiz, P. Georgiakakis, and M. Probonas. 2009. An audio-visual nest monitoring system for the study and manipulation of siblicide in Bearded Vultures Gypaetus barbatus on the island of Crete (Greece). Journal of Ethology 27:105-116.

Grønnesby, S., and T. Nygård. 2000. Using time-lapse video monitoring to study prey selection by breeding Goshawks Accipiter gentilis in Central Norway. Ornis Fennica 77:117-129.

Grundel, R. 1987. Determinants of nestling feeding rates and parental investment in the Mountain Chickadee. Condor 89:319-328.

Guzy, M. J., C. A. Ribic, and D. W. Sample. 2002. Helping at a Henslow's Sparrow nest in Wisconsin. Wilson Bulletin 114:407-409.
Gysel, L. W., and E. M. Davis, Jr. 1956. A simple automatic photographic unit for wildlife research. Journal of Wildlife Management 20:451-453.

Hanula, J. L., and K. E. Franzreb. 1995. Arthropod prey of nestling Red-cockaded Woodpeckers in the upper coastal plain of South Carolina. Wilson Bulletin 107:485-495.

Hernandez, F., D. Rollins, and R. Cantu. 1997. An evaluation of Trailmaster ${ }^{\circledR}$ camera systems for identifying ground-nest predators. Wildlife Society Bulletin 25:848-853.

Herranz, J., M. Yanes, and F. Suárez. 2002. Does photo-monitoring affect nest predation? Journal of Field Ornithology 73:97-101.

Honza, M., and C. Moskát. 2008. Egg rejection behaviour in the Great Reed Warbler (Acrocephalus arundinaceus): the effect of egg type. Journal of Ethology 26:389-395.

Hudson, M. R., and D. M. Bird. 2006. An affordable computerized camera technique for monitoring bird nests. Wildlife Society Bulletin 34:1455-1457.

Hussell, D. J. T. 1974. Photographic records of predation at Lapland Longspur and Snow Bunting nests. Canadian Field-Naturalist 88:503-506.

King, D. I., R. M. DeGraaf, P. J. Champlin, and T. B. Champlin. 2001. A new method for wireless video monitoring of bird nests. Wildlife Society Bulletin 29:349-353.

King, D. I., and R. M. DeGraaf. 2006. Predators at bird nests in a northern hardwood forest in New Hampshire. Journal of Field Ornithology 77:239-243.

Liebezeit, J. R., and T. L. George. 2003. Comparison of mechanically egg-triggered cameras and timelapse video cameras in identifying predators at Dusky Flycatcher nests. Journal of Field Ornithology 74:261-269.

Margalida, A., S. Ecolan, J. Boudet, J. Bertran, J. Martinez, and R. Heredia. 2006. A solar-powered transmitting video camera for monitoring cliff-nesting raptors. Journal of Field Ornithology 77:7-12.

McRae, S. B., P. J. Weatherhead, and R. Montgomerie. 1993. American Robin nestlings compete by jockeying for position. Behavioral Ecology and Sociobiology 33:101-106.

Momose, K., F. Sato, A. Kajita, and K. Saitou. 2003. Observations of breeding activity of Short-tailed Albatross Diomeda albatrus by satellite portable phone. Journal of the Yamashina Institute for Ornithology 34:314-319.

Morris, A. J., and J. J. Gilroy. 2008. Close to the edge: predation risks for two declining farmland passerines. Ibis 150(Suppl. 1):168-177.

Nathan, A., S. Legge, and A. Cockburn. 2001. Nestling aggression in broods of a siblicidal kingfisher, the Laughing Kookaburra. Behavioral Ecology 12:716-725. 
Pechacek, P. 2005. Use of non-stop video surveillance to monitor breeding activity of primary cavity nesters in remote areas. Acta Ethologica 8:1-4.

Pierce, A. J., and K. Pobprasert. 2007. A portable system for continuous monitoring of bird nests using digital video recorders. Journal of Field Ornithology 78:322-328.

Pietz, P. J., and D. A. Granfors. 2000. Identifying predators and fates of grassland passerine nests using miniature video cameras. Journal of Wildlife Management 64:71-87.

Proudfoot, G. A. 1996. Miniature video-board camera used to inspect natural and artificial nest cavities. Wildlife Society Bulletin 24:528-530.

Reif, V., and R. Tornberg. 2006. Using time-lapse digital video recording for a nesting study of birds of prey. European Journal of Wildlife Research 52:251-258.

Richardson, T. W., T. Gardali, and S. H. Jenkins. 2009. Review and meta-analysis of camera effects on avian nest success. Journal of Wildlife Management 73:287-293.

Royama, T. 1959. A device of an auto-cinematic foodrecorder. Tori 15:20-24.

Rutz, C., L. A. Bluff, A. A. S. Weir, and A. Kacelnik. 2007. Video cameras on wild birds. Science 318:765-765.

Sabine, J. B., J. M. Meyers, and S. H. Schweitzer. 2005. A simple, inexpensive video camera setup for the study of avian nest activity. Journal of Field Ornithology 76:293-297.

Sanders, M. D., and R. F. Maloney. 2002. Causes of mortality at nests of ground-nesting birds in the Upper Waitaki Basin, South Island, New Zealand: a 5-year video study. Biological Conservation 106:225-236.

Stake, M. M., and D. A. Cimprich. 2003. Using video to monitor predation at Black-capped Vireo nests. Condor 105:348-357.

Stevens, D. K., G. Q. A. Anderson, P. V. Grice, K. Norris, and N. Butcher. 2008. Predators of Spotted Flycatcher Muscicapa striata nests in southern England as determined by digital nest-cameras. Bird Study 55:179-187.

Thompson, F. R., III, and D. E. Burhans. 2003. Predation of songbird nests differs by predator and between field and forest habitats. Journal of Wildlife Management 67:408-416.

Thompson, F. R., III, and D. E. Burhans. 2004. Differences in predators of artificial and real songbird nests: evidence of bias in artificial nest studies. Conservation Biology 18:373-380.

Thompson, F. R., III, W. Dijak, and D. E. Burhans. 1999. Video identification of predators at songbird nests in old fields. Auk 116:259-264. 